\title{
Variable Beige Adipocyte Morphology in Obese Rats by Different Times of Melatonin Administration
}

\author{
Variación de la Morfología del Adipocito Beige en Ratas Obesas \\ Según los Diferentes Tiempos de Administración de Melatonina
}

Kalmukova Olesia ${ }^{1}$; Yurchenko Alona ${ }^{2}$; Savchuk Olexii ${ }^{2}$ \& Dzerzhynsky Mykola ${ }^{1}$

KALMUKOVA, O.; YURCHENKO, A.; SAVCHUK, O. \& DZERZHYNSKY, M. Variable beige adipocyte morphology in obese rats by different times of melatonin administration. Int. J. Morphol., 38(3):737-746, 2020.

SUMMARY: This study aimed to evaluate changes in beige adipocytes at different times of melatonin administration, in the morning (ZT01) or in the evening (ZT11), at $30 \mathrm{mg} / \mathrm{kg}$ daily by gavage for 7 weeks or continuously with drinking water in the term of high-calorie diet-induced obesity (HCD). Melatonin received at ZT11 or with drinking water resulted in an increased area of the browning zone in the subcutaneous white adipose tissue (sWAT), even in rats with HCD (compared with Control or HCD, respectively). The beige adipocyte and lipid droplet area after melatonin use were reduced compared to those with HCD and Control, in all administration modes (group ZT01 showed smaller changes compared to ZT11 or with drinking water groups). The fibrosis level decreased and significantly differed in HCD ZT01, HCD ZT11, and HCD water compared to that in HCD; moreover, the lowest value determined in HCD water, reached the control parameters. Furthermore, the IL-1b and IL-8 level was decreased in the HCD groups under melatonin treatment at ZT11 or with drinking water compared to that in HCD. The obtained results suggest that melatonin promotes sWAT browning in rats with diet-induced obesity and influences morphological signs of normal rats depending on the time of administration. Different functional activity of beige adipocytes was observed after melatonin was used depending on the time of administration, resulting in heat production and lipolysis (the relative mass of visceral fat was likewise diminished). More rapid browning was observed when melatonin treatment was performed at $1 \mathrm{~h}$ before lights-off (ZT11) or continuously via drinking water. Melatonin acted on beige adipocytes of obese rats through changing some parameters such as the area of adipocytes and lipid drops, the number of lipid drops, the relative area browning of sWAT, and the level of tissue fibrosis.

KEY WORDS: Chronobiology; High-calorie diet; Fibrosis; IL-1b; Adipose tissue.

\section{INTRODUCTION}

Melatonin is the hormone of the pineal gland, which has beneficial effects on the immune system, adipose tissue, and other tissues during metabolic disease (Xu, et al., 2017). However, melatonin can induce the appearance of beige adipocytes that are the potential target for obesity treatment through the dissipation of extra lipid for heat production (McMillan \& White, 2015). These adipocytes appear in white adipose tissue, but are similar to brown adipocytes in morphology and function, as they contain many mitochondria, store lipids in the form of several droplet inclusions (in contrast to white adipocytes, which deposited lipids in one large drop), express uncoupling protein 1 (UCP1) and provide heat production. However, beige adipocytes also have distinctive features from brown adipocytes: first, they are not a typical point in development; and second, they are derived from Myf5-negative progenitors (Wu et al., 2013). Beige adipocytes can differentiate from mesodermal stem cells, precursors of smooth muscles (along with white adipocytes) or by transdifferentiation from mature white adipocytes (this process is called browning of white adipose tissue [WAT]) (Merlin et al., 2016). The appearance of beige adipocytes can be stimulated in several ways: activation of the central nervous system by sympathetic modulation signals in WAT; effect of immune cells; or by direct action on white adipocytes and their precursors (Harms $\&$ Seale, 2013). The sympathetic nervous system carries out its modulation through the action of norepinephrine. However, systemic introduction of norepinephrine as a

\footnotetext{
${ }^{1}$ Department of Cytology, Histology and Reproductive Medicine, Educational and Scientific Center "Institute of Biology and Medicine," Taras Shevchenko National University of Kyiv, Kyiv, Ukraine.

${ }^{2}$ Department of Biochemistry, Educational and Scientific Center "Institute of Biology and Medicine," Taras Shevchenko National University of Kyiv, Kyiv, Ukraine.
} 
therapeutic agent in the body has many side effects including activation of the cardiovascular system. A promising candidate for direct activation of beige adipocytes is melatonin as its receptors have been found on white adipocytes (Dubocovich \& Markowska, 2005). In addition, long-term administration of melatonin in doses higher than the physiological level, has no significant side effects in humans (Grigg-Damberger \& Ianakieva, 2017).

In vitro studies have shown that beige adipocytes have almost the same thermogenic potential as brown adipocytes due to UCP1-expression (Ikeda et al., 2018). Expression of UCP1 is important for obesity therapy, and because in the absence of UCP1-mediated diet-induced thermogenesis, obesity is augmented even in the obesity-resistant $129 \mathrm{~S}$ mouse strain (Luijten et al., 2019).

Convincing evidence from animal models indicates that enhancement of the function of brown adipocytes, beige adipocytes, or both of these types of cells may be effective in the treatment of type 2 diabetes and obesity (Kaisanlahti \& Glumoff, 2019). In addition, there is now a large variety of factors and pathways that can potentially be aimed at increasing these therapeutic effects. Many thermogenic inducers such as irisin, Bmp8b, orexin, natriuretic peptide, and melatonin have been identified as having an effect on the physiology of brown and beige fat (McMillan \& White).

Obesity development is characterized by low-grade inflammation, immune cell migration in WAT, proinflammatory cytokine production, and fibrosis (Ellulu et al., 2017). Subcutaneous white adipose tissue (sWAT) contributes via production of adipokines and cytokines to both inflammation and insulin resistance in metabolic syndrome and hence is a co-conspirator with the macrophages contributing to both these processes (Jialal \& Devaraj, 2018). Fibrosis of WAT is associated with adipocyte hypertrophy, hypoxia, and lack of angiogenesis (Choe et al., 2016). Moreover, beige adipocyte biogenesis is inversely correlated with the development of adipose tissue fibrosis in sWAT (Hasegawa et al., 2018).

One of the topical issues in chronopharmacology is the choice of an effective time of drug administration to increase useful effects and reduce side effects (McKenna et al., 2018). An additional interesting issue is the varying sensitivity of organisms to melatonin over the course of the day, as manifested by the differences in specific membrane and nuclear receptor expression in cells (Bartness et al., 1993). Therefore, the aim of this study was to evaluate the morphology and functional status of beige adipocytes from subcutaneous WAT at different times of melatonin administration under the development of high-calorie diet-induced obesity.

\section{MATERIAL AND METHOD}

Animals and experimental design. Experiments were carried out on 80 albino non-linear male rats with an initial body mass of $110 \pm 10 \mathrm{~g}$. Animals were kept under standard vivarium conditions with controlled temperature and with ad libitum access to food and water. Artificial illumination, 12/12 $\mathrm{h}$ was used; light was switched on at 7.00 (ZT00) and switched off at 19.00 (ZT12).

All experiments on animals were performed in compliance with the international principles of the European Convention for the Protection of Vertebrate Animals used for Experimental and Other Scientific Purposes (Strasbourg, 1986), Directive 2010/63/EU of the European Parliament and of the Council of 22 September 2010 on the protection of animals used for scientific purposes, Article 26 of the Law of Ukraine "On the Protection of Animals from Cruelty" (No. 3447-IV, dated February 21, 2006), as well as all norms of bioethics, biological safety, and the general ethical principles of experiments on animals adopted by the First National Congress of Ukraine on Bioethics (September, 2001).

For the first week, all rats had ad libitum access to standardized food "Purina rodent chow" and water. On the 8th day, animals were randomly divided into two groups (24 animals in each groups). Rats of the first group were fed with a standard ration $(3.81 \mathrm{kcal} / \mathrm{g})$, whereas those of the second group received a high-calorie diet (HCD) $(5.35 \mathrm{kcal} /$ g). The high-calorie chow included $60 \%$ standard food composition, $10 \%$ pork fat, $10 \%$ hen eggs, $9 \%$ sucrose, 5 $\%$ peanut, $5 \%$ dry milk, and $1 \%$ vegetable oil. To confirm the development of obesity the animals were weighed one time a week until the average body gain reached a significant difference of at least $30 \%$ between the two groups. After that, each group was divided into four subgroups ( 6 animals in each subgroup): 1) rats without treatment (Control and HCD group), 2) rats that continuously consumed melatonin in drinking water ( $\mathrm{M}$ water and $\mathrm{HCD}$ water group), 3) rats administered melatonin by gavage in the morning ZT01 (1 $\mathrm{h}$ after light-on) (M ZT01 and HCD ZT01) and 4) rats administered melatonin by gavage in the evening ZT11 $(1 \mathrm{~h}$ before light-off) (M ZT11 and HCD ZT11) (Fig. 1).

Melatonin (Alcon Biosciences, USA) was administered each day at the dose of $30 \mathrm{mg} / \mathrm{kg}$ during 7 weeks. For groups $\mathrm{M}$ water and HCD water, the necessary melatonin dose was diluted in $20-30 \mathrm{ml}$ of drinking water according to the calculation of the daily mean value of drinking water consumption volume per animal. Water bottles were covered with aluminum foil to protect from light. For groups M ZT01, HCD ZT01, M ZT11, and HCD ZT11, 


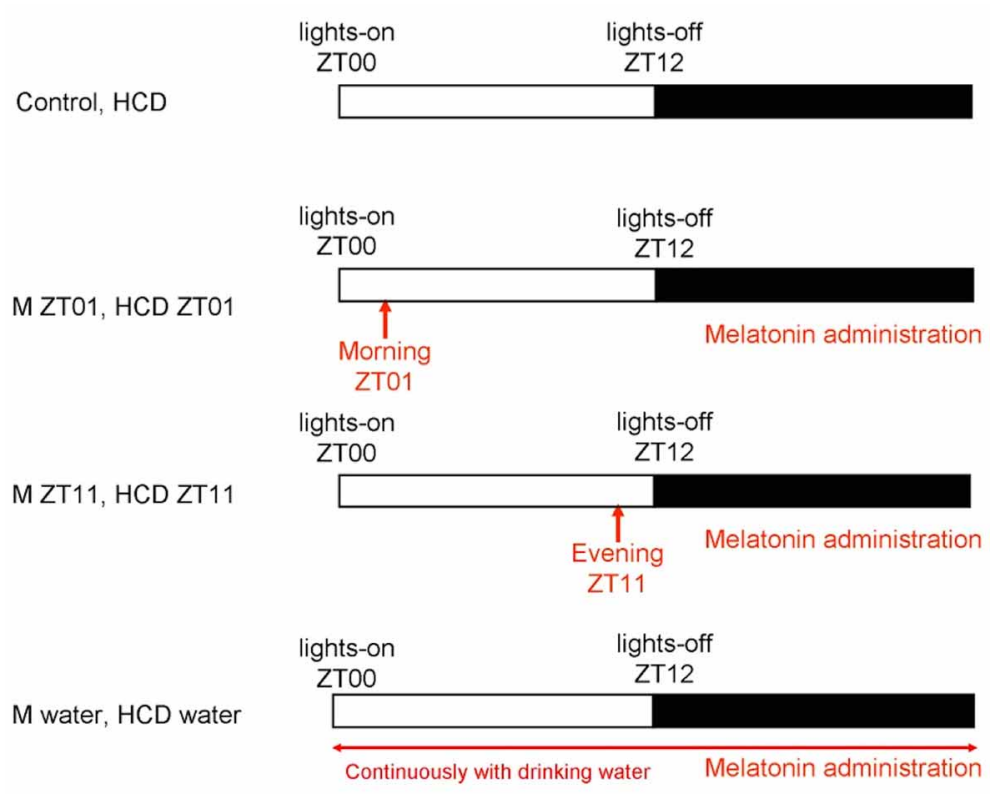

Fig. 1. Scheme of melatonin administration to experimental groups.
Histochemical analysis of tissue collagen content (fibrosis level) in inguinal white adipose tissue. Detection of collagen fibers was carried out using histochemical Van Gieson trichrome staining with addition of hematoxylin to visualize nuclei (Mishra et al., 2015). For quantitative determination of tissue collagen content microphotographs were obtained using an objective with $4 ¥$ magnification; for each subsequent microphotography, the field of view was moved to the right, retaining $20 \%$ of the previous field until the entire cut was taken. To create one large composite panoramic image, the cross-linking software Adobe Photoshop CS6 (Adobe Systems, USA) was used. From each image, the area of the red-stained region (red - collagen fibers) was calculated and expressed as a percentage of the total area (Spencer et al., 2011). the melatonin dose $(30 \mathrm{mg} / \mathrm{kg})$ was diluted in $2.0 \mathrm{ml}$ water and was administrated by gavage in accordance with the time of the day (ZT01 or ZT11). Melatonin was dissolved in a minimum volume of absolute ethanol and diluted in drinking water with a final concentration of $0.066 \%(\mathrm{w} / \mathrm{v})$ ethanol.

Food and water consumption were measured daily at the same time (09:00 to 10:00 h) and body weights were determined once a week. Body weight gain, relative daily food ( $\mathrm{kcal} /$ day/g body weight) and relative daily water consumption ( $\mathrm{ml} /$ day/g body weight) was determined for each rat.

Macroscopic analysis. On the last day of the experiment, animals were decapitated, and their blood was collected for subsequent biochemical analysis; subcutaneous posterior WAT (inguinal, gluteal, and dorsolumbal regions) and visceral WAT (epididymal, retroperitoneal, perirenal fat pads) were dissected and immediately weighed. sWAT was also photographed for determining the relative area of browning sWAT.

Histological examination was performed to characterize the morphology and functional status of beige adipocytes from sWAT. Fragments of sWAT in the size of 1 $¥ 1 \mathrm{~cm}$ were fixed in $4 \%$ paraformaldehyde in $0.1 \mathrm{M}$ phosphate buffer for $72 \mathrm{~h}$, after which they were dehydrated and embedded into paraffin according to a standard procedure. From the paraffin blocks, $5 \mu \mathrm{m}$ sections were prepared and were stained with hematoxylin and eosin.
Subsequent research was performed using a light microscope Olympus BX41 (Japan). Microphotographs were obtained using the Olympus DP20 (Japan) digital camera and the QuickPHOTO MICRO software (Promicra, Czech Republic). The cross-sectional area of beige adipocytes, relative area of browning iWAT, the number of lipid droplets per cell, and tissue fibrosis (the area occupied by collagen fibers) were measured using ImageJ software (National Institutes of Health, USA).

Biochemical analysis of serum IL-1b and IL-8 cytokine levels by enzyme-linked immunosorbent assay (ELISA) were performed. ELISA was performed in microplates with sorption capability according to the general procedure for soluble proteins. The antigen, pre-diluted in $0.1 \mathrm{M} \mathrm{NaHCO} 3$ buffer, $\mathrm{pH} 9.6$, to a concentration of 10 $\mathrm{mg} / \mathrm{ml}$, was incubated in 96-well plates at $4{ }^{\circ} \mathrm{C}$ for $12 \mathrm{~h}$. Removal of the unbinding antigen was carried out by threefold washing with a buffer for immobilization. Incubation was carried out in PBS pH 7.4. Non-specific binding sites were blocked by incubating with $5 \%$ skimmed milk powder for 60 minutes in a thermostat at $37^{\circ} \mathrm{C}$, followed by threefold washing with PBS containing $0.1 \%$ tween-20. Then, primary IL-1b rabbit antibody (Santa Cruz Biotechnology) / IL-8 rabbit antibody (Abcam) was added and incubated at $37^{\circ} \mathrm{C}$ for $1 \mathrm{~h}$. At the end of the incubation, the microplate wells were washed and treated with appropriate anti-rabbit goat antibodies (Santa Cruz Biotechnology), conjugated to horseradish peroxidase and incubated at $37^{\circ} \mathrm{C}$ for $1 \mathrm{~h}$. The wells were again washed three times with $0.1 \%$ tween-20 working buffer and incubated with the enzyme substrate for 
colorimetric analysis $(1 \mathrm{mg} / \mathrm{ml}$ tetramethylbenzidine (TMB) in $50 \mathrm{mM}$ phosphate citrate buffer $\mathrm{pH} 5.0$ from $0.013 \%$ $\mathrm{H}_{2} \mathrm{O}_{2}$, respectively) for $1 \mathrm{~h}$ at $37^{\circ} \mathrm{C}$. Optical absorbance was measured at $492 \mathrm{~nm}$ wavelength on a microplate reader, mQuantTM (BioTek Instruments, Inc., USA). The cytokine quantity was expressed as conditional units in the calculation to the total protein content in the serum. The cytokine level was expressed in percentages compared to the control value that was taken as $100 \%$.

Statistical analysis of the obtained results was conducted using Statistica 6.0 (StatSoft, USA) software. The normality of data distribution was determined by the ShapiroWilk criterion. To assess the validity of the revealed changes, parametric (Student t-test for two-samples) and nonparametric (Mann-Whitney U-test for the independent groups) methods of variation statistics were used with a posteriori Bonferroni test, the difference was considered significant at $\mathrm{p}<0.05$. The obtained results are presented as $\mathrm{M} \pm \mathrm{SEM}$ (mean \pm standard error of mean).

\section{RESULTS AND DISCUSSION}

At the first stage, we conducted macroscopic analysis of subcutaneous posterior white adipose tissue (Fig. 2). In the control group, browning regions appeared in 2 sitesinguinal and gluteal. After melatonin administration in group M ZT01 or M ZT11, two browning zones remained and became visible, which were even darker than those in the control, while in group $\mathrm{M}$ water, two browning areas expanded and connected into one dark-brown site. During obesity development, the browning region was localized mainly in gluteal sites with a weak mark from the inguinal zone. In groups with obesity and melatonin introduction, we estimated inverse observations related to the two sites of browning; in HCD ZT11 or HCD water, they manifested as dark and precise zones (compared with HCD). Morphometric examination showed (Fig. 3) that in the HCD groups, the relative area of browning iWAT was decreased compared to that in the control by $68 \%$. HCD ZT01 displayed a significant reduction by $60 \%$ compared to the control without a statistically significant difference. In group HCD ZT11, the value for the relative area of browning iWAT showed an intermediate level, significantly different from the control which was $20 \%$ smaller, and in HCD higher by about 2.5-fold. In HCD water, the relative area of browning iWAT reached the control level and differed from HCD by about 3-fold. Similar effects of melatonin for induction of browning in iWAT were observed in Zucker diabetic fatty rats, which are a genetically modified rat strain, after melatonin treatment $(10 \mathrm{mg} / \mathrm{kg}$ every day) in drinking water (Jiménez-Aranda et al., 2013). However, the data about the impact of melatonin on iWAT in animals with diet-induced obesity (alimentary) or without it are absent. The group with standard diet and melatonin administration (excluding $\mathrm{M}$ ZT01) also showed changes in the relative area of browning iWAT: their value increased by $55 \%$ and by $64 \%$ in M ZT11 and M water, respectively.

Histological observation suggested that the selected zone of iWAT contains beige adipocytes, as they have a distinguished morphology from white adipocytes (Fig. 4) and resemble brown adipocytes as polygonal cells with a round central-located nucleus, and many separate lipid droplets and mitochondria in the cytoplasm. White adipocytes, unlike beige and brown adipocytes, have a characteristic spherical cell shape with a flattened peripherallocated nucleus, because almost all the space of the

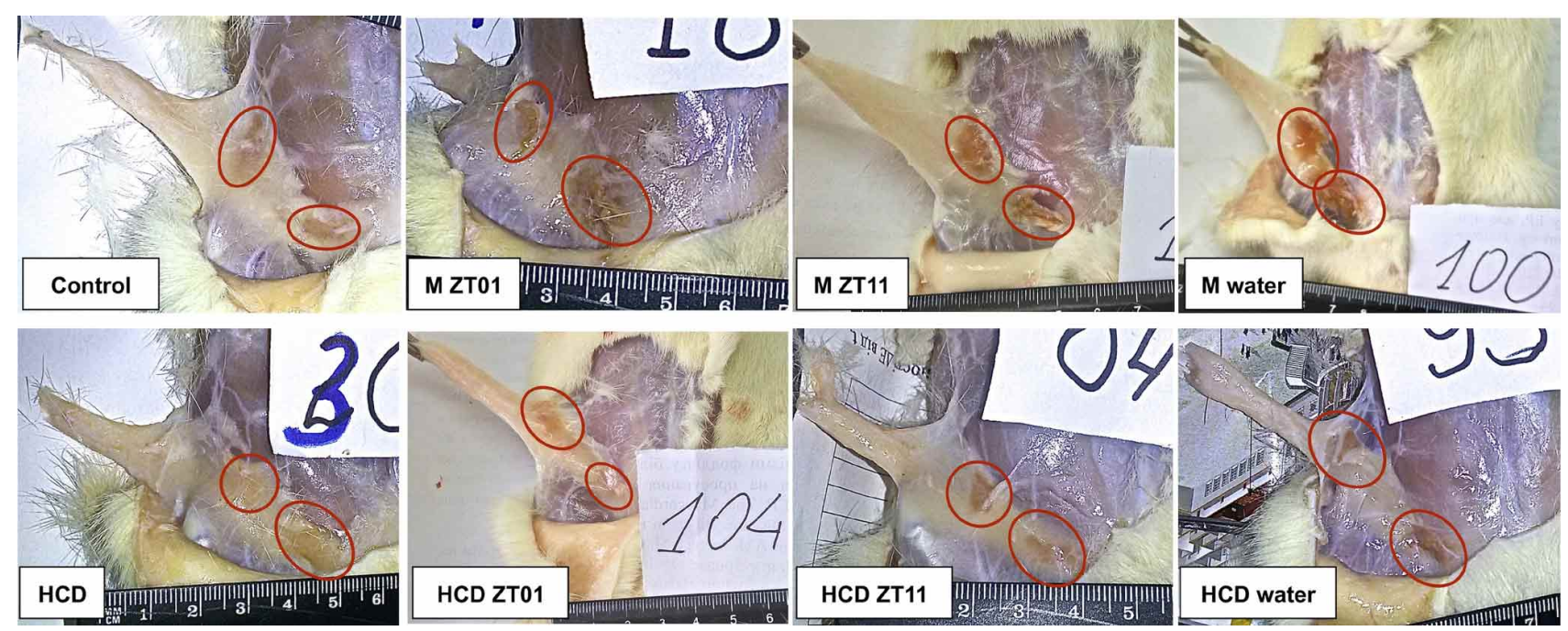

Fig. 2. Subcutaneous posterior white adipose tissue of rats. Red circle - browning region of sWAT. 


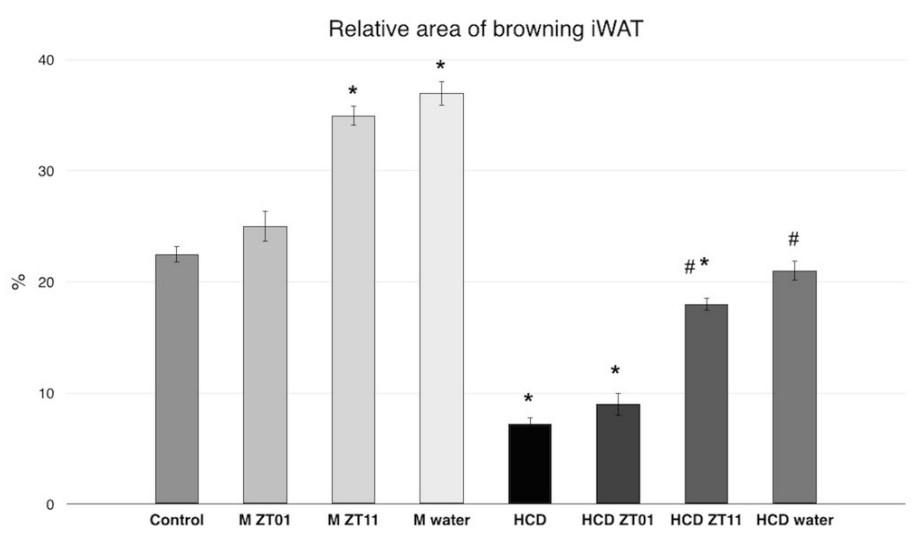

cytoplasm is occupied by one large lipid droplet. Under obesity development (HCD group) beige adipocytes have a negligible presence in iWAT and change their morphology-looking like white adipocytes with a few lipid droplets, a peripheral-located nucleus, and a bigger size of cells than that in beige adipocytes. After melatonin use in the group with HCD (HCD ZT01,

Fig. 3. Results of morphometric analysis for the relative area of browning sWAT. Data are presented as the $\mathrm{M} \pm \mathrm{SEM}$;

$*-p<0.05$ compared with the control value,

\# - $p<0.05$ compared HCD with the groups HCD ZT01, HCD ZT11, and HCD water.
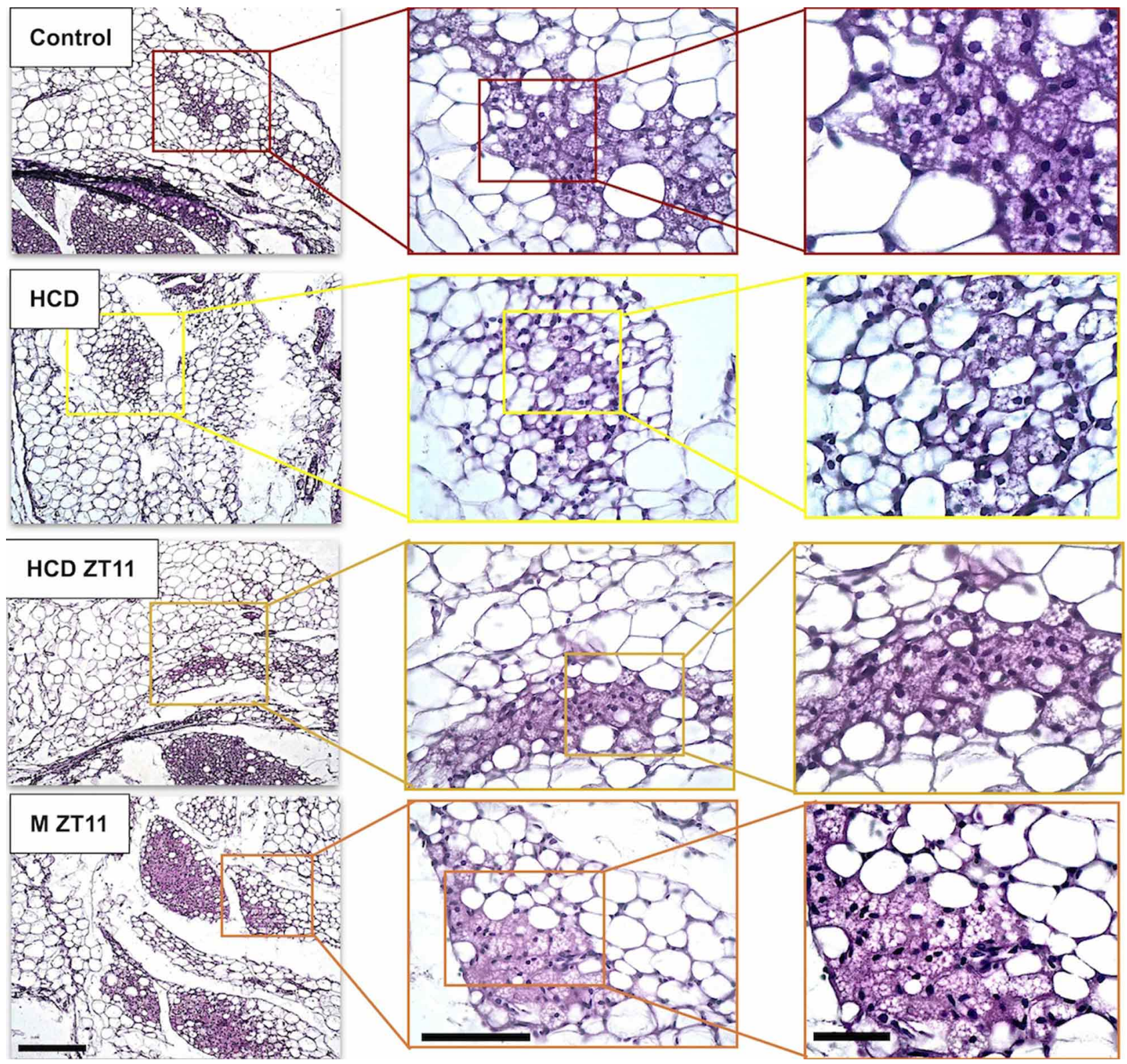

Fig. 4. Microphotographs of rats' iWAT sections: hematoxylin-eosin staining; scale bar 100, 50, $20 \mu \mathrm{m}$. 
HCD ZT11, and HCD water), the frequency of beige adipocytes was higher than that in HCD and they demonstrated a classical brown adipocyte morphology, but in the HCD ZT01, HCD ZT11, and HCD water groups, they showed different manifestation of shape details. Further, in M ZT01, M ZT11, and M water groups without obesity, the frequency of beige adipocytes in the microscopic field of view was large than that in the control group.

This observation is confirmed by the morphometric analysis of cells and the lipid droplets area, as well as the number of lipid droplets in each cell (Fig. 5). During obesity, the area of beige adipocytes increases by $54 \%$ and the area of lipid droplets increases by 2.3 -fold, whereas the number of lipid droplets decreases by 3 -fold compared with that in the control group. These changes suggest reduction of thermogenic function and use of lipids mainly for deposition, as also occurs in brown adipose tissue under diet-induced obesity when obese mice showed more unilocular adipocytes compared to the more multilocular adipocytes present in mice on a normal diet due to the increase in free fatty acid levels (Alcalá et al., 2017). Melatonin is induced in the groups with HCD (HCD ZT01, HCD ZT11, HCD water) compared to that in the HCD group resulting in a significant decline of beige adipocytes and in the lipid droplets area, even to the control values: the area of beige adipocytes in the group HCD water and the area of lipid droplets in the HCD ZT11 group. Moreover, in HCD water the area of lipid droplets was decreased compared to that in the control by
$40 \%$ and was equal to that in the groups M ZT01, M ZT11, and $\mathrm{M}$ water, stimulated only by melatonin without dietconsumption. Reduction of the lipid droplets area in M ZT01, M ZT11, and M water was accompanied by a decrease in the beige adipocytes area and an increase in the lipid droplets number compared to the control by $8 \%, 17 \%, 24 \%$, and by $55 \%, 67 \%$, respectively (in $\mathrm{M}$ water the lipid droplets number was increased 2-fold). A similar change in the growth of lipid droplets number in each cell was observed in HCD ZT01, HCD ZT11, and HCD water compared to that in HCD amount by $67 \%, 2.8$-fold (have reached control level), and 3.5 -fold (more than control by $17 \%$ ), respectively. This shift in beige adipocyte morphology after melatonin use can be associated with an increased functional activity of thermogenesis, mitochondrial biogenesis, and lipolysis, as shown in vivo (Liu et al., 2019) and in vitro (Kato et al., 2015) in previous studies.

Histochemical examination of sWAT tissue collagen content (Fig. 6). In the control group, collagen fibers were mostly located in the interlobular septum, whereas in the HCD group, they were additionally observed around hypertrophied white adipocytes, which provides the rigidity of adipose tissue parenchyma during obesity. After melatonin use in the HCD ZT01, HCD ZT11, and HCD water groups, an evident reduction in collagen fiber deposition was observed in the septum, as well as around adipocytes. In M water, M ZT01, and M ZT11 groups, no significant changes in the deposition of collagen fibers were noted. In the HCD
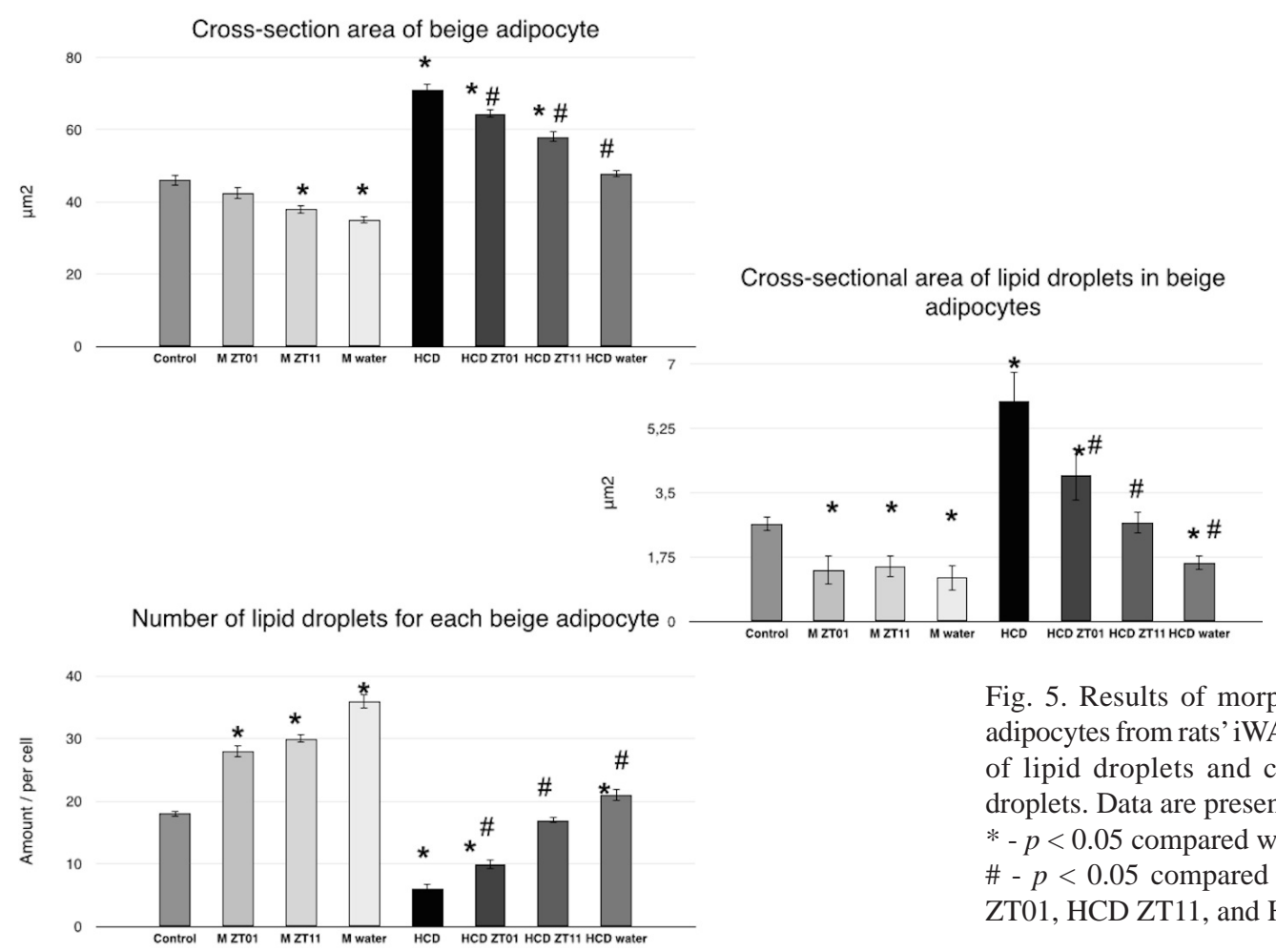

Fig. 5. Results of morphometric analysis for beige adipocytes from rats' iWAT: cross-section area, number of lipid droplets and cross-sectional area of lipid droplets. Data are presented as the $\mathrm{M} \pm \mathrm{SEM}$;

$*-p<0.05$ compared with control value,

$\#-p<0.05$ compared HCD with the groups HCD ZT01, HCD ZT11, and HCD water. 

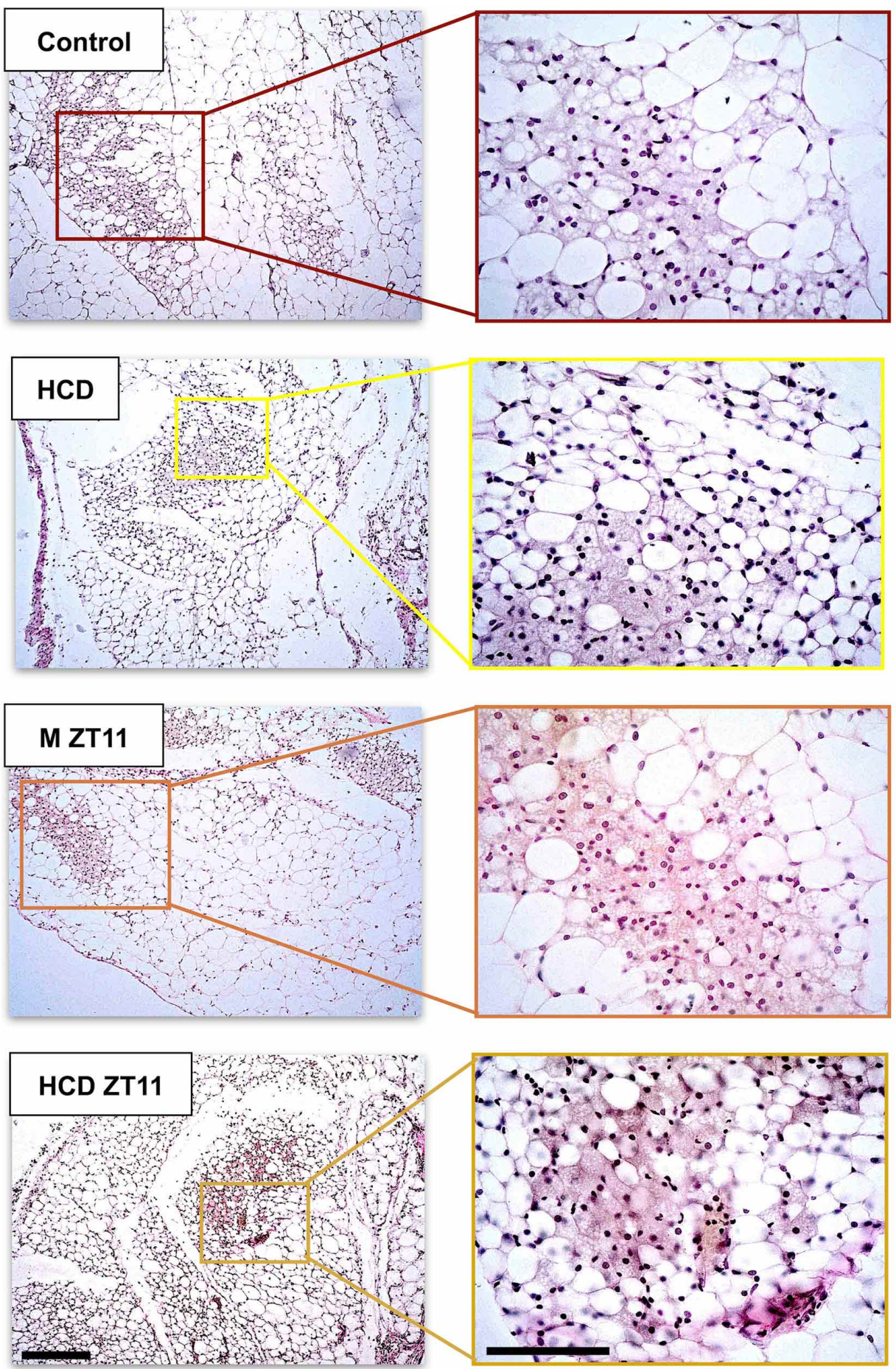

Fig. 6. Microphotographs of histochemical staining to detect collagen content of rats' sWAT sections: Van Gieson's staining; scale bar 100, $50 \mu \mathrm{m}$.

group, the relative area of collagen fibers (Fig. 7) was increased by 3.5 -fold compared to the control group, which can be predicted as tissue fibrosis development. In the group with melatonin treatment and $\mathrm{HCD}$, the synthesis and deposition of collagen fibers was reduced: compared to $\mathrm{HCD}$ in HCD water the level of fibrosis was less than 3 times, in $\mathrm{HCD}$ ZT11 it was -2.4 times, and in HCD ZT01, it was -2 times. Melatonin administration to rats with a standard diet did not affect the development of sWAT fibrosis and the increased amount of collagen fibers.

Biochemical study of the plasma proinflammatory cytokine levels demonstrated increased levels of IL- $1 \mathrm{~b}$ and IL- 8 by $22 \%$ and $34 \%$, respectively in the HCD group compared to the control (Fig. 7). Morning melatonin administration did not influence the levels of IL- $1 \mathrm{~b}$ and IL- 8 in rats with obesity (HCD ZT01 group) compared to those in the HCD group, and they increased by 14 $\%$ and $19 \%$ compared to the control. In the groups HCD ZT11 and HCD water, decreases in the level of IL- $1 \mathrm{~b}$ at $19 \%$ and $28 \%$, and in IL-8 at $26 \%$ and $35 \%$, were respectively observed compared to the HCD group. In M ZT01, M ZT11, and $\mathrm{M}$ water, melatonin administration did not change the IL-1b and IL-8 levels. IL-1b is reported to attenuate b3adrenoreceptor-induced beige adipocyte formation via oxidative stress and mitochondrial dysfunction (Okla et al., 2018). Thus, reduction of IL- $1 \mathrm{~b}$ due to melatonin is an additional stimulation mechanism for beige adipocytes appearance.

General data about weight change (Table I). Weight gain rates during the last 6 weeks of the experiment demonstrate a significant difference between the control and HCD group, with a 2-times increase in HCD, whereas after melatonin administration, it was intermediate HCD ZT01 and did not differ from the Control / HCD groups. However, with administration of melatonin in the evening, 


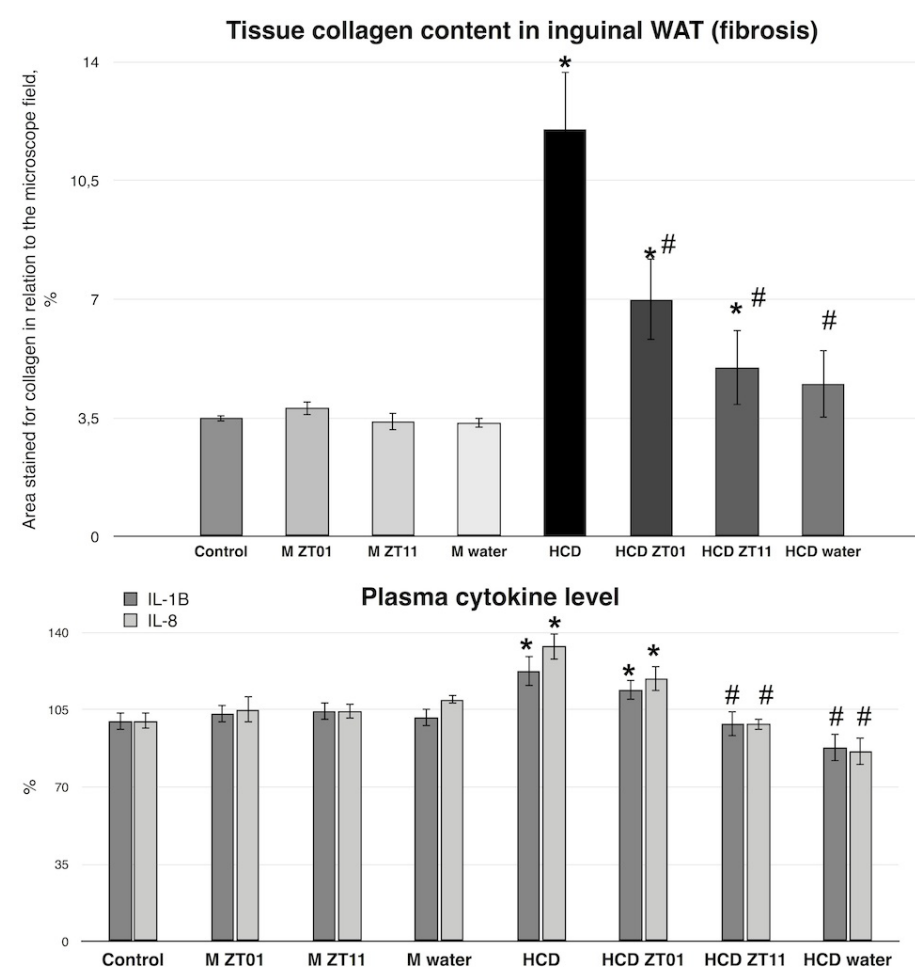

Fig. 7. Results of morphometric analysis for tissue collagen content in sWAT (fibrosis): area stained for collagen in relation to the microscope field, \%; and biochemical data of serum IL-1b and IL-8 cytokines levels. Data are presented as the $\mathrm{M} \pm \mathrm{SEM} ;{ }^{*}-p<$ 0.05 compared with control value, \# - $p<0.05$ compared HCD with group HCD ZT01, HCD ZT11, HCD water.

HCD ZT11 showed a decreased weight gain rate by 2 times (compared with HCD) and reached the control value, similar to the HCD water group (showed a decrease of 2.5 times compared to HCD). Animals that received a standard diet and melatonin (M ZT01, M ZT11, M water) did not show changes in their weight gain rate in case of different modes of administration. Similar results were observed after melatonin treatment in drinking water $(10 \mathrm{mg} / \mathrm{kg})$ in highfat fed Wistar rats (Ríos-Lugo et al., 2010), where morning (between 6:00 and 7:00) intraperitoneal administration at a dose of $1 \mathrm{mg} / \mathrm{kg}$ in did not contribute to decreasing the weight gain rate (Kitagawa et al., 2012).
The relative mass of sWAT in HCD was increased by $44 \%$ compared to that in the control. In HCD ZT01, HCD ZT11, and HCD water groups, the relative mass of sWAT did not significantly differ from $\mathrm{HCD} /$ control group, but a tendency to decrease was observed. Only in the M ZT01 group, a difference was observed compared to the control by a $14 \%$ decrease.

Relative visceral fat weight in HCD increased by $65 \%$ compared to the control. HCD ZT01 usually showed an intermediate level: more than the control by $18.5 \%$, and less than HCD by $28 \%$. HCD ZT11 and HCD water showed similar results: they did not differ from the control, but show a significant difference compared to HCD by $38.5 \%$. We observed a significant difference in the relative visceral fat weight in M ZT01, M ZT11, and M water by $48 \%$, $47 \%$ and $40 \%$, respectively. This can be associated with activation of thermogenesis via brown and beige adipocytes (Kalmukova \& Dzerzh?nsky, 2018).

The obtained results suggest that melatonin promotes sWAT browning in rats with diet-induced obesity and influences beige adipocyte morphology in the sWAT of normal rats. A difference was observed in the activation of beige adipocytes function in sWAT when melatonin treatment was performed $1 \mathrm{~h}$ after (ZT01) light-on or before (ZT11) lights-off, and continuously via drinking water. However, according to the general score analysis in the difference between melatonin administration modes (Table II), the best efficacy was observed with continuous administration through drinking water, followed by evening administration at $1 \mathrm{~h}$ before light-off, and finally, morning administration after 1 $\mathrm{h}$ light-on. Partially similar results were obtained in Sprague Dawley rats with HCD (Prunet-Marcassus et al., 2003), but melatonin $(30 \mathrm{mg} / \mathrm{kg}$ ) was administrated at ZT04 and ZT11 for 3 weeks by gavage; melatonin administration at ZT04 showed no effect on some metabolic (glucose and triglycerides) and hormonal (insulin and leptin) parameters. However, in our study, morning melatonin treatment ZT01 for 7 weeks showed a significant difference compared to

Table I. Baseline information about changing body weight parameters.

\begin{tabular}{|c|c|c|c|c|c|c|c|c|}
\hline Parameter & Control & M ZT01 & M ZT11 & M water & $\mathrm{HCD}$ & HCD ZT01 & HCD ZT11 & HCD water \\
\hline Weight gain rate (\%) & $7.7 \pm 1.86$ & $9.1 \pm 2.65$ & $7 \pm 2.57$ & $8.5 \pm 2.67$ & $14 \pm 1.81^{*}$ & $9.2 \pm 3.37$ & $6.5 \pm 2^{\#}$ & $5.5 \pm 1.91^{\#}$ \\
\hline $\begin{array}{l}\text { Relative mass of } \\
\operatorname{sWAT}(\%)\end{array}$ & $1.34 \pm 0.05$ & $1.15 \pm 0.05^{*}$ & $1.2 \pm 0.17$ & $1.21 \pm 0.1$ & $1.92 \pm 0.36^{*}$ & $1.46 \pm 0.23$ & $1.5 \pm 0.1$ & $1.42 \pm 0.25$ \\
\hline $\begin{array}{l}\text { Relative vi sceral fat } \\
\text { weight ( } \%)\end{array}$ & $17.8 \pm 0.3$ & $9.2 \pm 0.9^{*}$ & $9.4 \pm 2.3^{*}$ & $10.7 \pm 0.7^{*}$ & $29.3 \pm 3.1 *$ & $21.1 \pm 1.4 * \#$ & $17.9 \pm 1.8^{\#}$ & $18 \pm 2^{\#}$ \\
\hline
\end{tabular}

Data are presented as the $\mathrm{M} \pm \mathrm{SEM} ; *-p<0.05$ compared with control value, $\#-p<0.05$ compared HCD with the groups HCD ZT01, HCD ZT11, and HCD water. 


\begin{tabular}{lccc}
\hline & HCD ZT01 & HCD ZT11 & HCD water \\
\hline Macroscopic analysis & 1 & $2.5(\&)$ & $3.5(\&)$ \\
$\begin{array}{l}\text { Morphometric analysis: } \\
\text { area of beige adipocytes }\end{array}$ & 2 & $2.5(\&)$ & $3.5(\&)$ \\
$\begin{array}{l}\text { Morphometric analysis: } \\
\text { lipid droplets area }\end{array}$ & 2 & $3.5(\&)$ & $3.5(\&)$ \\
$\begin{array}{l}\text { Morphometric analysis: } \\
\text { number of lipid droplets per cells }\end{array}$ & 2 & $3.5(\&)$ & $2.5(\&)$ \\
$\begin{array}{l}\text { Tissue collagen content } \\
\text { Cytokines analysis }\end{array}$ & 2 & 2 & $3.5(\&)$ \\
Relative visceral fat weight & 1 & $3.5(\&)$ & $3.5(\&)$ \\
Total & 2 & 3 & 3 \\
\hline
\end{tabular}

Table II. The general score analysis in difference between time of administration of melatonin. Score: 3 - reach control value, 2 - intermediate value between control and HCD, 1 - no significant difference compared to $\mathrm{HCD} ;+0.5$ point if $\&-p<$ 0.05 when comparing HCD ZT01 with the groups HCD ZT11 and HCD water.
HCD in tissue collagen content, area of beige adipocytes and lipid droplets, lipid droplets number in beige adipocytes, and relative visceral fat weight; the values of these parameters were mostly different from the control values.

ACKNOWLEDGEMENTS. The authors thank Kyryk V.M., Ph.D., M.D., Cell and Tissue Culture Laboratory, The State Institute of Genetic and Regenerative Medicine of Ukrainian National Academy of Medical Sciences, Kyiv, Ukraine, for the final paper reading.

KALMUKOVA, O.; YURCHENKO, A.; SAVCHUK, O. \& DZERZHYNSKY, M. Variación de la morfología del adipocito beige en ratas obesas según los diferentes tiempos de administración de melatonina. Int. J. Morphol., 38(3):737-746, 2020.

RESUMEN: Este estudio tuvo como objetivo evaluar los cambios en los adipocitos beige en diferentes momentos de la administración de melatonina, en la mañana (ZT01) o por la noche (ZT11). Se administraron $30 \mathrm{mg} / \mathrm{kg}$ diariamente por sonda durante 7 semanas o continuamente con agua potable durante el periodo de obesidad inducida por una dieta alta en calorías (HCD). La melatonina recibida en ZT11 o con agua potable resultó en un aumento de área dorada en tejido adiposo blanco subcutáneo (sWAT), incluso en ratas con HCD (en comparación con Control o $\mathrm{HCD}$, respectivamente). El área de gotas de lípidos y adipocitos de color beige después del uso de melatonina se redujo en comparación con aquellos con HCD y Control, en todos los modos de administración (el grupo ZT01 mostró cambios más pequeños en comparación con ZT11 o con grupos de agua potable). El nivel de fibrosis disminuyó y difirió significativamente en HCD ZT01, HCD ZT11 y agua HCD, en comparación con el HCD; además, el valor más bajo determinado en agua HCD alcanzó los parámetros de control. Además, el nivel de IL-1b e IL-8 disminuyó en los grupos HCD bajo tratamiento con melatonina en ZT11 o con agua potable en comparación con el de HCD. Los resultados obtenidos sugieren que la melatonina promueve el dorado sWAT en ratas con obesidad inducida por la dieta e influye en los signos morfológicos de las ratas normales dependiendo del momento de la administración. Se observó una actividad funcional diferente de los adipocitos de color beige después de usar melatonina dependiendo del tiempo de administración, dando como resultado la producción de calor y lipólisis (la masa relativa de grasa visceral también disminuyó). Se observó un ennegrecimiento más rápido cuando el tratamiento con melatonina se realizó $1 \mathrm{~h}$ antes de apagar las luces (ZT11) o de forma continua en grupos de agua potable. La melatonina actuó en los adipocitos beige de ratas obesas al cambiar algunos parámetros, como el área de adipocitos y gotas de lípidos, el número de gotas de lípidos, el área relativa de ennegrecimiento de sWAT y el nivel de fibrosis tisular.

PALABRAS CLAVE: Cronobiología; Dieta alta en calorías; Fibrosis; IL-1ß; Tejido adiposo.

\section{REFERENCES}

Alcalá, M.; Calderon-Dominguez, M.; Bustos, E.; Ramos, P.; Casals, N.; Serra, D.; Viana, M. \& Herrero, L. Increased inflammation, oxidative stress and mitochondrial respiration in brown adipose tissue from obese mice. Sci. Rep., 7(1):16082, 2017.

Bartness, T. J.; Powers, J. B.; Hastings, M. H.; Bittman, E. L. \& Goldman, B. D. The timed infusion paradigm for melatonin delivery: what has it taught us about the melatonin signal, its reception, and the photoperiodic control of seasonal responses? J. Pineal Res., 15(4):161-90, 1993.

Choe, S. S.; Huh, J. Y.; Hwang, I. J.; Kim, J. I. \& Kim, J. B. Adipose tissue remodeling: its role in energy metabolism and metabolic disorders. Front. Endocrinol. (Lausanne), 7:30, 2016.

Dubocovich, M. L. \& Markowska, M. Functional MT1 and MT2 melatonin receptors in mammals. Endocrine, 27(2):101-10, 2005.

Ellulu, M. S.; Patimah, I.; Khaza'ai, H.; Rahmat, A. \& Abed, Y. Obesity and inflammation: the linking mechanism and the complications. Arch. Med. Sci., 13(4):851-63, 2017.

Grigg-Damberger, M. M. \& Ianakieva, D. Poor quality control of over-thecounter melatonin: what they say is often not what you get. J. Clin. Sleep Med., 13(02):163-5, 2017.

Harms, M. \& Seale, P. Brown and beige fat: development, function and therapeutic potential. Nat. Med., 19(10):1252-63, 2013.

Hasegawa, Y.; Ikeda, K.; Chen, Y.; Alba, D. L.; Stifler, D.; Shinoda, K.; Hosono, T.; Maretich, P.; Yang, Y.; Ishigaki, Y.; et al. Repression of adipose tissue fibrosis through a PRDM16-GTF2IRD1 complex improves systemic glucose homeostasis. Cell Metab., 27(1):180-194e6, 2018. 
Ikeda, K.; Maretich, P. \& Kajimura, S. The common and distinct features of brown and beige adipocytes. Trends Endocrinol. Metab., 29(3):191200, 2018.

Jialal, I. \& Devaraj, S. Subcutaneous adipose tissue biology in metabolic syndrome. Horm. Mol. Biol. Clin. Investig., 33(1), 2018.

Jiménez-Aranda, A.; Fernández-Vázquez, G.; Campos, D.; Tassi, M.; Velasco-Perez, L.; Tan, D. X.; Reiter, R. J. \& Agil, A. Melatonin induces browning of inguinal white adipose tissue in Zucker diabetic fatty rats. J. Pineal Res., 55(4):416-23, 2013.

Kaisanlahti, A. \& Glumoff, T. Browning of white fat: agents and implications for beige adipose tissue to type 2 diabetes. J. Physiol. Biochem., 75(1):110, 2019.

Kalmukova, O. O. \& Dzerzhnsky, M. E. The effects of different time of melatonin administration on differentiation and functional status of the brown adipocytes in vivo. Cell Organ Transpl., 6(1):80-5, 2018.

Kato, H.; Tanaka, G.; Masuda, S.; Ogasawara, J.; Sakurai, T.; Kizaki, T.; Ohno, H. \& Izawa, T. Melatonin promotes adipogenesis and mitochondrial biogenesis in 3T3-L1 preadipocytes. J. Pineal Res., 59(2):267-75, 2015.

Kitagawa, A.; Ohta, Y. \& Ohashi, K. Melatonin improves metabolic syndrome induced by high fructose intake in rats. J. Pineal Res., 52(4):403-13, 2012

Liu, K.; Yu, W.; Wei, W.; Zhang, X.; Tian, Y.; Sherif, M.; Liu, X.; Dong, C.; Wu, W.; Zhang, L.; et al. Melatonin reduces intramuscular fat deposition by promoting lipolysis and increasing mitochondrial function. J. Lipid Res., 60(4):767-82, 2019.

Luijten, I. H. N.; Feldmann, H. M.; von Essen, G.; Cannon, B. \& Nedergaard, $\mathrm{J}$. In the absence of UCP1-mediated diet-induced thermogenesis, obesity is augmented even in the obesity-resistant $129 \mathrm{~S}$ mouse strain. Am. J. Physiol. Endocrinol. Metab., 316(5):E729-E740, 2019.

McKenna, H.; van der Horst, G. T. J.; Reiss, I. \& Martin, D. Clinical chronobiology: a timely consideration in critical care medicine. Crit. Care, 22:124, 2018.

McMillan, A. C. \& White, M. D. Induction of thermogenesis in brown and beige adipose tissues: molecular markers, mild cold exposure and novel therapies. Curr. Opin. Endocrinol. Diabetes Obes., 22(5):347-52, 2015.

Merlin, J.; Evans, B. A.; Dehvari, N.; Sato, M.; Bengtsson, T. \& Hutchinson, D. S. Could burning fat start with a brite spark? Pharmacological and nutritional ways to promote thermogenesis. Mol. Nutr. Food Res., 60(1):18-42, 2016.

Mishra, N. S. S.; Wanjari, S. P.; Parwani, R. N.; Wanjari, P. V. \& Kaothalker, S. P. Assessment of collagen and elastic fibres in various stages of oral submucous fibrosis using Masson's trichrome, Verhoeff vangieson and picrosirius staining under light and polarizing microscopy. J. Dent. Spec., 3(2):170-5, 2015.

Okla, M.; Zaher, W.; Alfayez, M. \& Chung, S. inhibitory effects of toll-like receptor 4, NLRP3 inflammasome, and interleukin-1b on white adipocyte browning. Inflammation, 41(2):626-42, 2018.

Prunet-Marcassus, B.; Desbazeille, M.; Bros, A.; Louche, K.; Delagrange, P.; Renard, P.; Casteilla, L. \& Pénicaud, L. Melatonin reduces body weight gain in Sprague Dawley rats with diet-induced obesity. Endocrinology, 144(12):5347-52, 2003.

Ríos-Lugo, M. J.; Cano, P.; Jiménez-Ortega, V.; Fernández-Mateos, M. P.; Scacchi, P. A.; Cardinali, D. P. \& Esquifino, A. I. Melatonin effect on plasma adiponectin, leptin, insulin, glucose, triglycerides and cholesterol in normal and high fat-fed rats. J. Pineal Res., 49(4):342-8, 2010.

Spencer, M.; Unal, R.; Zhu, B.; Rasouli, N.; McGehee Jr., R. E.; Peterson, C. A. \& Kern, P. A. Adipose tissue extracellular matrix and vascular abnormalities in obesity and insulin resistance. J. Clin. Endocrinol. Metab., 96(12):E1990-8, 2011.

Wu, J.; Cohen, P. \& Spiegelman, B. M. Adaptive thermogenesis in adipocytes: Is beige the new brown? Genes Dev., 27(3):234-50, 2013.

Xu, P.; Wang, J.; Hong, F.; Wang, S.; Jin, X.; Xue, T. \& Zhai, Y. Melatonin prevents obesity through modulation of gut microbiota in mice. J. Pineal Res., 62(4):10.1111/jpi.12399, 2017.
Corresponding author:

Kalmukova Olesia

03127, Kyiv, Hlushkova Avenue, 2

Educational and Scientific Center

"Institute of Biology and Medicine" of Taras Shevchenko

National University of Kyiv

UKRAINE

Email: olesiakalmukova28@gmail.com

Received: 01-10-2019

Accepted: 22-10-2019 